\title{
Local failure in high grade prostate cancer: the importance of local and systemic therapy
}

\author{
Amar U. Kishan ${ }^{1}$, Howard M. Sandler ${ }^{2}$ \\ ${ }^{1}$ Department of Radiation Oncology, University of California, Los Angeles, CA 90095, USA; ${ }^{2}$ Cedars Sinai Medical Center, Los Angeles, CA 90095, USA \\ Correspondence to: Amar U. Kishan, MD. 200 UCLA Medical Plaza, Suite B265, Los Angeles, CA 90095, USA. Email: aukishan@mednet.ucla.edu. \\ Response to: Levitin RB, Hamstra DA. Local control matters. Transl Androl Urol 2020;9:991-6. \\ Mula-Hussain L, Roy S, Malone S. Implications of local failure on overall prognosis in aggressive prostate cancer. Transl Androl Urol 2020;9:1001-5.
}

Submitted May 04, 2020. Accepted for publication Jun 05, 2020.

doi: $10.21037 /$ tau-20-910

View this article at: http://dx.doi.org/10.21037/tau-20-910

We welcome the two Editorial Comments discussing our recent meta-analysis evaluating the importance of local failure following definitive radiotherapy for high Gleason grade prostate cancer (1-3). We would first like to address the Editorial Comment from Mula-Hussain and colleagues, who discuss limitations of our study (2). Many of these limitations were reported as such in our original manuscript. We do of course acknowledge that our metaanalysis included trials that enrolled men many years ago, which is an important limitation to consider. However, that fact has never prevented the conclusions from these trials influencing current care standards. Specifically, the results of the RTOG 9202 and EORTC 22961 trials defined the standard of hormone therapy in high-risk prostate cancer for decades following their publication (including to the present day) (4). All but the most recent trials of hormone therapy duration, in fact, utilized doses of radiation on the order of 70 Gy. For example, 70 Gy was the radiation dose used in the recently published PCSIV trial, which ultimately led to numerous professional societies allowing for 18 months of hormonal therapy as a minimal duration for high risk disease (5). Similarly, more than $50 \%$ of the patients enrolled on the recently published TROG 03.04 trial were treated to 66-70 Gy (6). A quarter of the patients on the EORTC 22991 trial, which was included in this meta-analysis, received 70 Gy (7). The large randomized RTOG 0126 trial, which had a standard-of-care arm dose of $70.2 \mathrm{~Gy}$, was finally published in 2018 and failed to show an improvement in prostate cancer-specific mortality or overall survival (8). So long as the conclusions from these trials are still considered relevant, the use of lower dose of radiation in the studies including in our meta-analysis should not be used to inherently diminish the credibility of its conclusions.

With regards to other technological advancements that were mentioned, such as MRI-guided treatment planning and use of hydrogel spacers, we agree that these may improve the risk benefit ratio of dose-escalation. However, none of these advancements were in place for essentially any of the large, published trials in prostate cancer radiotherapy. As with dose considerations, these technological advancements do not inherently detract from our meta-analysis.

Other important limitations the authors mention are (I) the heterogeneity of the local failure definition and (II) the inability to account for the impact of the primary Gleason grade and secondary Gleason grade. The latter point in particular is important, and imbalances in bulk or grade of disease between those experiencing local failure and those who did not could have confounded the analysis. As a recurring theme, however, none of the prospective randomized trials in prostate cancer radiotherapy have thus far accounted for this difference, either.

The limitations notwithstanding, we posit that there are two major conclusions from our meta-analysis, just as Levitin and Hamstra indicate in their Editorial Comment The first is that local failure is a poor prognostic factor even in high grade prostate cancer, despite the competing risk of distant failure. The second is that some patients experience a clinical local failure prior to experiencing a distant metastasis. One mechanistic explanation for this would be the so-called second wave theory, wherein a local failure seeds a distant metastasis. This would be supported by the results of the aforementioned RTOG 0126 trial, which 
enrolled patients with intermediate risk disease only (8). Though this trial did not identify an overall survival benefit to dose escalation, it identified a difference in the cumulative incidence of distant metastases favoring the high-dose arm. Levitin and Hamstra nicely summarize the growing body of literature supporting the role of improved local control in high grade prostate cancer.

We also acknowledge that the existence of a second wave cannot be proven by our data. Even if the second wave occurred, it would not represent the primary mode of distant metastatic failure in patients with high grade disease. Therefore, we completely agree that systemic therapy is still critical in this patient population, since the risk of occult micrometastases at presentation is substantial. Indeed, prolonged durations of ADT may be particularly important in this patient population and novel anti-androgens should be considered as well (9). Rather than disputing this, our meta-analysis suggests a potential additional role for enhancing local control in terms optimizing clinical outcomes. Importantly, ADT itself, as a systemic agent, is still thought to enhance local control through a variety of mechanisms, including but not limited to potential radiosensitization and/or inhibition of radiation-induced increases in androgen signaling. Thus, improving local control and improving systemic therapy are not mutually exclusive but rather complementary (10).

We certainly agree with both Editorial Comments that prospective studies are needed to validate our findings, which are based on post-hoc analyses. We hope that insights into the combinatorial benefit of enhanced systemic control (e.g., with apalutamide or enzalutamide) and enhanced local control (e.g., with a brachytherapy boost) can be gained from prospective studies such as ATLAS (NCT02531516) and ENZARAD (NCT02446444). Both trials are designed to enroll patients with a high risk of occult micrometastatic disease and are stratified by use of a brachytherapy boost.

\section{Acknowledgments}

Funding: None.

\section{Footnote}

Provenance and Peer review: This article was commissioned by the editorial office, Translational Andrology and Urology. The article did not undergo external peer review.

Conflicts of Interest: Both authors have completed the
ICMJE uniform disclosure form (available at http://dx.doi. org/10.21037/tau-20-910). Dr. Kishan reports grants and personal fees from ViewRay, Inc., personal fees from Varian Medical Systems, Inc., from Intelligent Automation, Inc., other from Janssen, Inc., outside the submitted work. Dr. Sandler reports grants from American College of Radiology/NRG Oncology, personal fees from Janssen Pharmaceuticals, from Vivos, outside the submitted work.

Ethical Statement: The authors are accountable for all aspects of the work in ensuring that questions related to the accuracy or integrity of any part of the work are appropriately investigated and resolved.

Open Access Statement: This is an Open Access article distributed in accordance with the Creative Commons Attribution-NonCommercial-NoDerivs 4.0 International License (CC BY-NC-ND 4.0), which permits the noncommercial replication and distribution of the article with the strict proviso that no changes or edits are made and the original work is properly cited (including links to both the formal publication through the relevant DOI and the license). See: https://creativecommons.org/licenses/by-nc-nd/4.0/.

\section{References}

1. Kishan AU, Chu FI, King CR, et al. Local Failure and Survival After Definitive Radiotherapy for Aggressive Prostate Cancer: An Individual Patient-level Meta-analysis of Six Randomized Trials. Eur Urol 2020;77:201-8.

2. Mula-Hussain L, Roy S, Malone S. Implications of Local Failure on Overall Prognosis in Aggressive Prostate Cancer. Transl Androl Urol 2020;9:1001-5.

3. Levitin RB, Hamstra DA. Local Control Matters. Transl Androl Urol 2020;9:991-6.

4. NCCN. NCCN Clinical Practice Guidelines in Oncology: Prostate Cancer. 2019. Available online: http://www.nccn. org/professionals/physician_gls/pdf/prostate.pdf. Accessed $11 / 30 / 2015$.

5. Nabid A, Carrier N, Martin AG, et al. Duration of Androgen Deprivation Therapy in High-risk Prostate Cancer: A Randomized Phase III Trial. Eur Urol 2018;74:432-41.

6. Denham JW, Joseph D, Lamb DS, et al. Shortterm androgen suppression and radiotherapy versus intermediate-term androgen suppression and radiotherapy, with or without zoledronic acid, in men with locally advanced prostate cancer (TROG 03.04 RADAR): 10-year 
results from a randomised, phase 3, factorial trial. Lancet Oncol 2019;20:267-81.

7. Bolla M, Maingon P, Carrie C, et al. Short Androgen Suppression and Radiation Dose Escalation for Intermediate- and High-Risk Localized Prostate Cancer: Results of EORTC Trial 22991. J Clin Oncol 2016;34:1748-56.

8. Michalski JM, Moughan J, Purdy J, et al. Effect of Standard vs Dose-Escalated Radiation Therapy for Patients With Intermediate-Risk Prostate Cancer: The NRG Oncology RTOG 0126 Randomized Clinical Trial.

Cite this article as: Kishan AU, Sandler HM. Local failure in high grade prostate cancer: the importance of local and systemic therapy. Transl Androl Urol 2020;9(5):2315-2317. doi:10.21037/ tau-20-910
JAMA Oncol 2018;4:e180039.

9. Kishan AU, Wang X, Seiferheld W, et al. Association of Gleason Grade With Androgen Deprivation Therapy Duration and Survival Outcomes: A Systematic Review and Patient-Level Meta-analysis. JAMA Oncol 2019;5:91-6.

10. Joseph D, Denham JW, Steigler A, et al. Radiation Dose Escalation or Longer Androgen Suppression to Prevent Distant Progression in Men With Locally Advanced Prostate Cancer: 10-Year Data From the TROG 03.04 RADAR Trial. Int J Radiat Oncol Biol Phys 2020;106:693-702. 